\title{
The catalytic conversion of natural gas to useful products
}

\author{
J.R.H. Ross ${ }^{a}$, A.N.J. van Keulen ${ }^{\text {a,b }}$, M.E.S. Hegarty ${ }^{a}$, K. Seshan ${ }^{b}$ \\ ${ }^{\text {a }}$ Centre for Environmental Research, University of Limerick, Limerick, Ireland \\ ${ }^{\mathrm{b}}$ Faculty of Chemical Technology, University of Twente, 7500 AE Enschede, The Netherlands
}

\begin{abstract}
This paper gives a brief summary of some processes, direct and indirect, for the conversion of natural gas to useful products. It then proceeds to give an outline of some work from the authors' laboratories on subjects such as steam reforming, oxidative coupling and $\mathrm{CO}_{2}$ reforming of methane, paying particular attention to the development of novel catalysts for these processes.
\end{abstract}

Keywords: Catalytic conversion; Natural gas; $\mathrm{CO}_{2}$ reforming of methane; Steam reforming; Oxidative coupling

\section{Introduction}

Natural gas is defined as a combustible gas that occurs in porous rock of the earth's crust and is found with or near accumulations of crude oil [1]. It contains between 70 and $98 \%$ of methane, with higher hydrocarbons (ethane to hexane) present in quantities of up to a maximum $16 \%$, while diluents $\left(\mathrm{N}_{2}, \mathrm{CO}_{2}\right)$ can account for a maximum of $15 \%$, depending on the location from where it is produced. Some reservoirs also contain large amounts of sulphur-containing molecules, particularly $\mathrm{H}_{2} \mathrm{~S}$. The reserves of natural gas outstrip those of oil and, as a result, it is likely to become one of the main sources of carbon-based chemicals in the next century. Table 1 lists the currently proven reserves and consumption of oil, natural gas and coal.

Currently, the main use of natural gas is in (non-catalytic) combustion for heating purposes, while the only signiticant use in the (petro- chemical industry is for the production of hydrogen through steam reforming. Fig. 1 gives a summary of the various chemicals which can be produced from natural gas, together with the reaction pathways involved in these conversions.

In general, two different types of route for methane conversion to useful products can be distinguished: direct and indirect. The direct routes are one-step processes in which the natural gas is reacted with oxygen (or another oxidising species) to give the desired product directly. Apart from complete combustion for heating purposes (giving $\mathrm{CO}_{2}$ and water), all other possible processes are still at the research stage; this is mostly because the conversions and/or selectivities are insufficiently high for the reaction to be of interest for commercial application. For example, for the much-studied oxidative coupling reaction:

$2 \mathrm{CH}_{4}+1 / 2 \mathrm{O}_{2}=\mathrm{C}_{2} \mathrm{H}_{6}+\mathrm{H}_{2} \mathrm{O}$ 
Table 1

Proven world-wide reserves and yearly consumption of non-renewable energy resources (all figures are in billion (10 ${ }^{9}$ ) ton oil equivalent)

\begin{tabular}{lrrrrr}
\hline & \multicolumn{2}{c}{ Proven reserves } & & \multicolumn{2}{c}{ Yearly consumption } \\
\cline { 2 - 6 } & 1973 & 1983 & 1993 & 1983 & 1993 \\
\hline Crude oil & 80 & 92 & 144 & 2.6 & 3.3 \\
Natural gas & 40 & 79 & 120 & 1.5 & 1.8 \\
Coal & 330 & 510 & 470 & 2.1 & 2.2 \\
\hline
\end{tabular}

or

$2 \mathrm{CH}_{4}+\mathrm{O}_{2}=\mathrm{C}_{2} \mathrm{H}_{4}+2 \mathrm{H}_{2} \mathrm{O}$,

the highest $\mathrm{C}_{2+}$ yields which have been attained to date are between 20 and $22 \%$; a yield of ca. $30 \%$ would be needed for the reaction to be of commercial interest [2]. Interest in this reaction in Europe and the US has therefore waned considerably, although there are still a small number of activities in the area. However, the reaction still receives very considerable attention in a number of Asian countries, including China, as evidenced by the contributions from Chinese authors in this issue of Catalysis Today. Some of the work on this reaction carried out in the authors' laboratories will be summarised briefly in a later section.

The indirect route is a two step process whereby natural gas is first converted into synthesis gas (a mixture of $\mathrm{H}_{2}$ and $\mathrm{CO}$ ) via steam reforming, partial oxidation, $\mathrm{CO}_{2}$ reforming or a combination of two of these reactions; the synthesis gas is then converted into the desired product. For example, for the well-established steam reforming process, the reaction proceeds as follows:

$\mathrm{CH}_{4}+\mathrm{H}_{2} \mathrm{O}=\mathrm{CO}+3 \mathrm{H}_{2}$.

The composition of the synthesis gas may be altered by carrying out the water-gas shift reaction or its reverse:

$\mathrm{CO}+\mathrm{H}_{2} \mathrm{O}=\mathrm{CO}_{2}+\mathrm{H}_{2}$.

In one extreme, pure hydrogen can be produced, $\mathrm{CO}_{2}$ being removed from the mixture by absorption; in the other extreme, a mixture with $\mathrm{CO} / \mathrm{H}_{2}$ ratio of unity (or even lower) can be obtained. To illustrate the importance of synthesis gas, it is the main feed stock for the manufacture of for example hydrogen, ammonia, methanol, formaldehyde and acetic acid. Most of the hydrogen, produced by a combination of steam reforming and the water-gas shift reaction, is used in refinery operations. In 1991, US

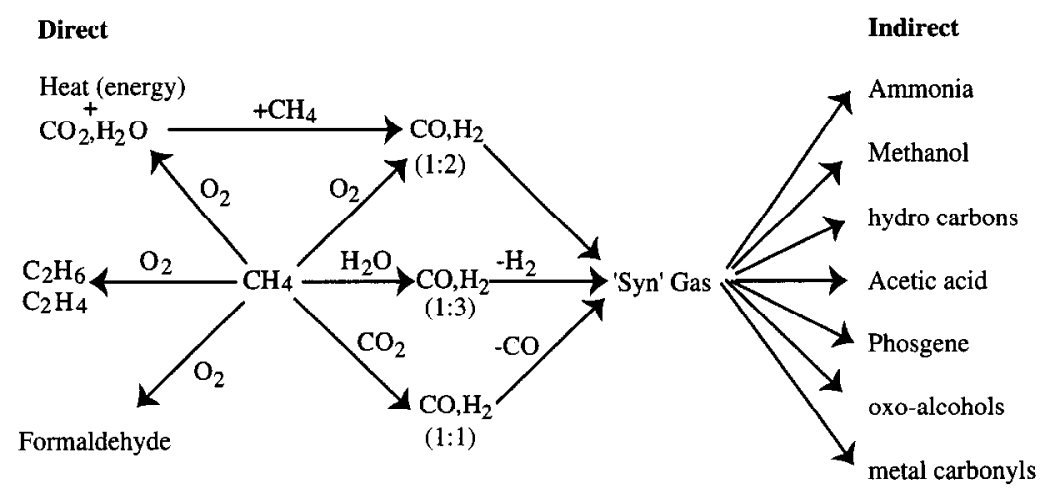

Fig. 1. Various direct and indirect routes for the production of useful chemicals from natural gas (the indirect also includes hydrogen). 
refineries produced about a third of their hydrogen requirement from steam reforming and partial oxidation [3], much of the balance being formed as by-products in other refinery operations. Due to the environmental regulations imposed on transportation fuels, an increasing demand for pure hydrogen is to be expected. Ammonia, which is the next largest utiliser of hydrogen, is one of the major chemicals produced world-wide. For methanol, the demand in 1995 is expected to be 23.90 mtpy (million tons per year) and this amount is likely to increase yearly due to larger demands for MTBE [4]; for formaldehyde, the current demand is $7.98 \mathrm{mtpy}$ while for acetic acid it is 1.87 mtpy.

This paper gives a brief review of the development of catalysts for three routes of methane conversion carried out in the authors' laboratories. The first catalyst described is one now used commercially for steam reforming of natural gas; various catalysts for the oxidative coupling of methane are then discussed; and finally, the development of $\mathrm{Pt} / \mathrm{ZrO}_{2}$ materials for the $\mathrm{CO}_{2}$ reforming of methane is outlined.

\section{Steam reforming}

Early work carried out at the University of Bradford (UK) in collaboration with a group at the Technical University of Delft (The Netherlands) led to a detailed understanding of the textural and structural factors dictating the activity and stability of co-precipitated nickelalumina materials originally developed by British Gas for the steam reforming of naphthas to form synthetic natural gas in the so-called catalytic rich gas (CRG) process [5-8]. The high activity and stability of these catalysts depends on the formation in the precipitation stage of a well-defined layer structure, 'hydrotalcite', in which brucite-like layers containing $\mathrm{Ni}^{2+}$ and $\mathrm{Al}^{3+}$ and $\mathrm{OH}^{-}$ions are separated from one another by 'interlayers' containing anions $\left(\mathrm{CO}_{3}^{2-}\right.$ in a well-prepared material $)$ as well as water molecules, the structure having an approximate molecular formula:

$\mathrm{Ni}_{6} \mathrm{Al}_{2}(\mathrm{OH})_{16} \cdot \mathrm{CO}_{3} \cdot 4 \mathrm{H}_{2} \mathrm{O}$.

The nature of the charge-balancing anion formed in the interlayer depends on the $\mathrm{pH}$ of precipitation and on the anions present in the precipitation solution; using nitrate salts and sodium carbonate as precipitant, two nitrate ions are incorporated per unit at lower $\mathrm{pH}$ values but these are replaced by single carbonate anions at higher $\mathrm{pH}(>\mathrm{ca} .7)$.

Subsequent work [9] showed that these materials could be modified by the addition of other cations such as $\mathrm{La}^{3+}$ to the formulation; lanthanum additions not only stabilised the structure of the final catalyst but also gave some increase in specific activity for methanation (the test reaction used to study the behaviour of the catalysts). It was further recognised that the La-modified hydrotalcite material could be incorporated within the macropores of a suitable preformed $\alpha$-alumina by filling the pores (by vacuum impregnation) with a urea-containing solution of the nitrates of $\mathrm{Ni}, \mathrm{La}$ and $\mathrm{Al}$, heating to ca. $130^{\circ} \mathrm{C}$ to bring about hydrolysis of the urea and precipitation of the hydrotalcite material, followed by calcination to decompose the hydrotalcite. These materials have the advantages of the very high mechanical and thermal stability of the $\alpha$-alumina combined with the high activities of the incorporated species. Although these catalysts were at first developed with the intention of using them for methanation purposes in chemical heat-pipe applications, tests were carried out with them which showed that they were very suitable as steam-reforming catalysts for hydrogen production from natural gas. They are now produced commercially by Dycat International who also make magnesiamodified formulations of the same materials using various differently shaped pieces of $\alpha$ alumina to minimise pressure drop through the reactor. One recent application of these catalysts is in the Midrex process in which syngas pro- 
duced by a combination of steam reforming and $\mathrm{CO}_{2}$ reforming is used to reduce iron ore, the resultant $\mathrm{CO}_{2}$ and water being recirculated for the reforming steps [10].

\section{Oxidative coupling of methane}

In 1982, a paper by Keller and Bhasin demonstrated that two molecules of methane could be coupled oxidatively (in a cyclic process) to produce ethane and ethylene [11]:

$\mathrm{CH}_{4}+1 / 2 \mathrm{O}_{2}=\mathrm{C}_{2} \mathrm{H}_{6}+\mathrm{H}_{2} \mathrm{O}$

$\mathrm{CH}_{4}+\mathrm{O}_{2}=\mathrm{C}_{2} \mathrm{H}_{4}+2 \mathrm{H}_{2} \mathrm{O}$.

Undesired by-products in the reaction are $\mathrm{CO}$ and $\mathrm{CO}_{2}$

$\mathrm{CH}_{4}+11 / 2 \mathrm{O}_{2}=\mathrm{CO}+2 \mathrm{H}_{2} \mathrm{O}$

$\mathrm{CH}_{4}+2 \mathrm{O}_{2}=\mathrm{CO}_{2}+2 \mathrm{H}_{2} \mathrm{O}$.

Shortly after the paper by Keller and Bhasin appeared, Baerns and his group demonstrated that it was possible to carry out the reaction under co-feed conditions and showed that $\mathrm{PbO}$ /alumina materials would catalyse the reaction with reasonable selectivities [12]. Thereafter, Lunsford and co-workers published an important paper describing the use of $\mathrm{Li}$ doped $\mathrm{MgO}$ catalysts for the reaction under co-feed conditions, demonstrating that methyl radicals formed at the surface of the catalyst may be desorbed from the surface and may combine to form cthane in the gas phase [13]. Work on methane coupling commenced at the University of Twente in 1985. Our preliminary work [14] showed that catalysts containing lead oxide were unstable under operating conditions due to the evaporation of metallic lead. Further, the $\mathrm{Li} / \mathrm{MgO}$ system was also unstable due to the evaporation of $\mathrm{LiOH}$ from the catalyst surface. A large number of catalyst formulations were examined during the next decade in the Twente laboratory. Of the various materials studied, one of the most stable was a $\mathrm{BaO} / \mathrm{CaO}$ mixture [15] and the most selective materials were those based on the $\mathrm{Li} / \mathrm{MgO}$ system but doped with various oxides, particularly tin oxide [16]; it was later shown that this facilitates the formation of a solid solution of $\mathrm{Li}_{2} \mathrm{SnO}_{3}$ in $\mathrm{MgO}$ and gives rise to the formation of $\mathrm{Li}_{2} \mathrm{Mg}_{3} \mathrm{SnO}_{6}$ and hence the stabilisation of the lithium content of the catalyst under the reaction conditions [17]. Another stable catalyst turned out to be one based on the $\mathrm{K} / \mathrm{Ca} / \mathrm{Ni}$ system first described by Heinemann et al. [18] who claimed that the catalyst gave very high selectivities to $C_{2}$ hydrocarbons. Detailed examination showed that this effect was only apparent as the $\mathrm{CO}_{2}$ formed in the early stages over this catalyst was adsorbed by the catalyst surface [19]. However, by changing the allover composition of the catalyst and calcining it at much higher temperatures than those used by Heinemann et al., a significant improvement in behaviour was found and the materials now gave yields of the order of $20 \%$, among the highest recorded in the literature under normal co-flow conditions [20]. Some of the work outlined above has been reviewed elsewhere [21].

\section{Carbon dioxide reforming of methane}

Even though research into the $\mathrm{CO}_{2}$ reforming reaction commenced in the 1920 s [22], it has recently attracted renewed interest [23,24]. Initially this renewed interest was a caused by a belief that the reaction offered a potential method of reducing the concentrations of $\mathrm{CO}_{2}$ emitted to the atmosphere but it was later recognised that the reaction would have an insignificant effect; at the best, the syngas produced could be converted to polymers or chemicals but the total amount used for these purposes would be very small compared with the total world-wide emissions of $\mathrm{CO}_{2}$. However, there is also a developing interest in the production of syngas with a low $\mathrm{H}_{2}$ : $\mathrm{CO}$ ratio for the production of molecules such as acetic acid or formaldehyde [4]. A novel series of catalysts for this reaction has been developed at the Univer- 


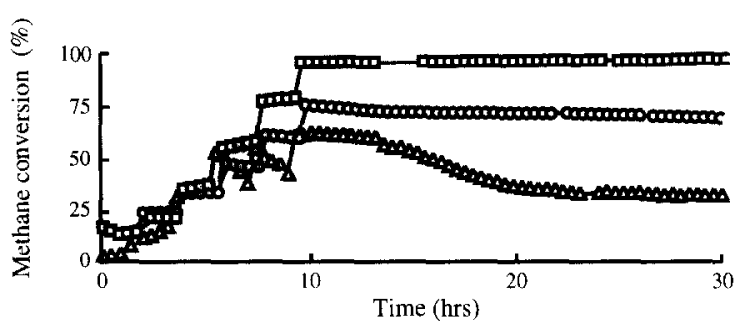

Fig. 2. The $\mathrm{CH}_{4}$ conversion vs time for several $1 \mathrm{wt} \% \mathrm{Pt}$ catalysts: $\square, \mathrm{Pt} / \mathrm{ZrO}_{2} ; \mathrm{O}, \mathrm{Pt} / \mathrm{TiO}_{2} ;$ and $\triangle, \mathrm{Pt} / \mathrm{Al}_{2} \mathrm{O}_{3}$. During the first $10 \mathrm{~h}$ on-stream, the temperature of reaction was raised at regular intervals from 550 to $800^{\circ} \mathrm{C} . \mathrm{CO}_{2} / \mathrm{CH}_{4}$ ratio $=2$.

sity of Limerick which appear to resist significant carbon laydown under reaction conditions close to those likely to be encountered under industrial conditions. Some of this work, which has been described in more detail elsewhere [25], will now be outlined.

Starting from the premise that a Group VIII metal would have to be used, the activity and stability of $\mathrm{Pt}$ on various different supports was first examined]. The oxides $\mathrm{ZrO}_{2}, \mathrm{TiO}_{2}$ and $\mathrm{Al}_{2} \mathrm{O}_{3}$ were selected for study as it had been reported in the literature that other supports such as $\mathrm{MgO}$, and $\mathrm{SiO}_{2}$ do not give active materials $[27,28]$; a $\mathrm{La}_{2} \mathrm{O}_{3}$ support was not examined in any detail as it fragmented under the reaction conditions employed. Fig. 2 shows the conversions of methane at a series of temperatures plotted as a function of time on stream for three catalysts containing approximately 1 wt\% of $\mathrm{Pt}$ on $\mathrm{ZrO}_{2}, \mathrm{TiO}_{2}$ and $\mathrm{Al}_{2} \mathrm{O}_{3}$. Even though at lower temperature not much difference is observed, at high temperatures it can be seen clearly that $\mathrm{Pt} / \mathrm{ZrO}_{2}$ is the most active and stable sample. The $\mathrm{Pt} / \mathrm{Al}_{2} \mathrm{O}_{3}$ sample deactivated due to carbon deposition, large amounts of carbon being detected on the material after use. The titania-supported material exhibited an intermediate behaviour.

The next step was to decide on which metal was most suitable for the active phase. As initial experiments showed that $\mathrm{Ni}, \mathrm{Co}$ and $\mathrm{Fe}$ samples were prone to coking [25], these materials were subsequently ignored and only the noble metals (e.g. Ir, Rh, Ru, Pd and Pt) were examined;

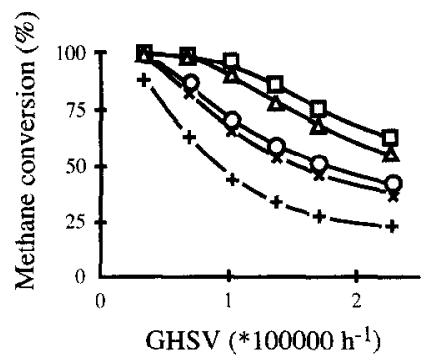

Fig. 3. $\mathrm{CH}_{4}$ conversion as a function of GHSV at $800^{\circ} \mathrm{C}$ for catalysts consisting of $\mathrm{Rh}(\triangle), \mathrm{Pt}(\square), \mathrm{Pd}(\mathrm{O}), \mathrm{Ir}(x)$ and $\mathrm{Ru}$ $(+)$, all at a content of $1 \mathrm{wt} \%$, supported on $\mathrm{ZrO}_{2}, \mathrm{CO}_{2} / \mathrm{CH}_{4}$ ratio $=2$.

based on the results described above, $\mathrm{ZrO}_{2}$, was used as the support. Fig. 3 shows the activities of these catalysts for methane conversion as a function of $\mathrm{GHSV}$ at $800^{\circ} \mathrm{C} . \mathrm{Pt} / \mathrm{ZrO}_{2}$ and $\mathrm{Rh} / \mathrm{ZrO}_{2}$ were the most active catalysts and they were stable over the relatively short tests shown. It was decided to continue the catalyst development work with the $\mathrm{Pl} / \mathrm{ZrO}_{2}$ system rather than the $\mathrm{Rh} / \mathrm{ZrO}_{2}$ system as $\mathrm{Rh}$ is likely to be too expensive for use in an industrial process, especially if large quantities of metal would be required. (Even though the current Rh price is approximately the same as that of $\mathrm{Pt}$ [29], the supply of this metal is limited and so a significant increase in the price would probably occur if large quantities were required for this or any other process.) Further work [25] showed that the activities of catalysts with $\mathrm{Pt}$ loadings between $0.25 \%$ and $1 \mathrm{wt} \%$ did differ not significantly but that to achieve a stable catalyst per-

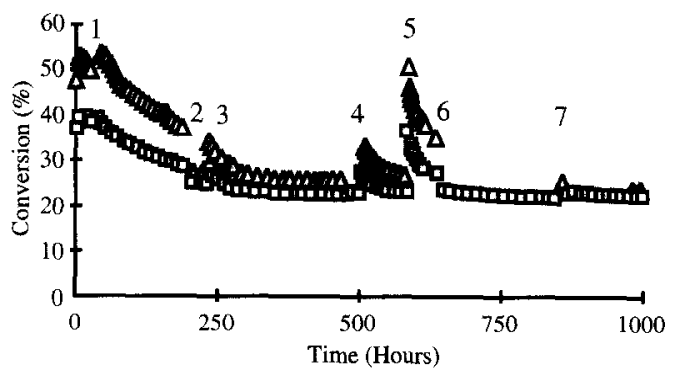

Fig. 4. $\mathrm{CH}_{4}$ and $\mathrm{CO}_{2}$ conversions as a function of time for a 0.5 wt $\% \mathrm{Pt} / \mathrm{ZrO}_{2}$ catalyst. Conditions: $1.9 \mathrm{~g}$ catalyst, $T$ varied from 650 (end of the catalyst bed) to $700^{\circ} \mathrm{C}$ (beginning of bed); $\mathrm{GHSV}=1600 \mathrm{~h} \mathrm{~h}^{-1} ; \mathrm{CO}_{2}: \mathrm{CH}_{1}=2: 1 ;$ gas mixture contained $5.7 \%$ $\mathrm{N}_{2}$ dilution. $(\triangle) \mathrm{CH}_{4}$ conversion, $(\square) \mathrm{CO}_{2}$ conversion. 
formance a Pt content of at least $0.5 \mathrm{wt} \%$ was needed. The platinum optimum loading was therefore chosen as $0.5 \mathrm{wt} \%$.

A sample of a $0.5 \mathrm{wt} \% \mathrm{Pt} / \mathrm{ZrO}_{2}$ catalyst was then subjected to a life-time test of $1000 \mathrm{~h}$ at ca. $700^{\circ} \mathrm{C}$ and the results are shown in Fig. 4 in which the $\mathrm{CH}_{4}$ and $\mathrm{CO}_{2}$ conversions are plotted as a function of time. During this experiments, there were a number of discontinuities in the results as a result of various experimental factors. For example, at the points 1, 3, 4 and 7, the reactor was by-passed by the reactant gases to allow one or other to be replaced, this resulting in a temporarily increase in the activity of the catalyst. At points 2 and 6 , the reaction temperature was allowed to drop to below $300^{\circ} \mathrm{C}$, resulting in a lower activity but more stable behaviour. Finally, at point 5 , the methane feed was temporarily cut off, this resulting in the activity regaining the initial value once more. After use, the catalyst revealed no extensive carbon deposition even though it would appear that the working catalyst has approximately a monolayer of carbon on its surface under reaction conditions. It would appear that the $\mathrm{Pt}-\mathrm{ZrO}_{2}$ combination works well because the zirconia encourages the adsorption of the $\mathrm{CO}_{2}$ which then reacts with any surface carbon to give two molecules of $\mathrm{CO}$; this reaction very probably occurs at the interface between the Pt and the zirconia. Further work is in progress to further establish this model.

Based on the performance of this $\mathrm{Pt} / \mathrm{ZrO}_{2}$ catalyst for the $\mathrm{CO}_{2}$-reforming reaction, an economic evaluation was performed [26]. This case study was based on the production of 180000 tonnes of acetic acid per year using the Monsanto process [30]; four different processes for the manufacture of the necessary syngas were considered: steam reforming, autothermal reforming, partial oxidation and $\mathrm{CO}_{2}$ reforming. The results of the evaluation showed that the $\mathrm{CO}_{2}$ reforming option has the lowest operating costs, about $20 \%$ lower than the other processes, this lower cost being mainly due to the lower feedstock requirements.
Further work on the $\mathrm{Pt} / \mathrm{ZrO}_{2}$ catalyst is currently under way. For example, it has been shown that the material is effective for a combination of $\mathrm{CO}_{2}$ and steam reforming or of $\mathrm{CO}_{2}$ reforming and partial oxidation; by using two different oxygen containing molecules simultaneously, different $\mathrm{H}_{2} / \mathrm{CO}$ ratios ranging from below 1.0 (pure $\mathrm{CO}_{2}$ reforming) to above 3.0 (steam reforming together with the water-gas shift reaction) can be achieved at will. High pressure experiments are also being conducted to examine whether the catalyst will withstand even more extreme conditions; the results obtained so far indicate that the catalyst is stable at pressures up to at least $10 \mathrm{Bar}$ and at temperatures of at least $800^{\circ} \mathrm{C}$.

\section{Conclusions}

It is likely that the non-catalytic combustion of methane will remain one of the main uses of natural gas for the foreseeable future. However, steam reforming is a major use of natural gas for the production of hydrogen in the petrochemical industry and for methanol synthesis. It is probable that there will be some limited expansion of the use of $\mathrm{CO}_{2}$ reforming or combinations of $\mathrm{CO}_{2}$ reforming and steam reforming for very specific purposes if the economics of the process indeed turn out to be favourable. It is less likely that methane coupling will be commercialised unless the economics of the process become much more favourable, for example by a relatively larger rise in the price of oil than that of natural gas. Further development of methane coupling is also possible if suitable methods can be found to combine the reaction with other chemical processes in order to optimise the energetics of the combined process and also if more economical methods (e.g. membrane separation) can be found to separate the $\mathrm{C}_{2}$ products from the other gases present in the reaction mixture exiting the catalytic reactor. 


\section{Acknowledgements}

The authors wish to acknowledge support from the European Commission for some of the work reported in this paper. The most recent work was funded under contract JOU2-CT920073 .

\section{References}

[1] Perry's Chemical Engineering Handbook, 6th ed., McGrawHill, New York, Section 9, p. 12.

[2] K. van der Wiele, $\mathrm{I}^{2}$ Procestechnol., 1 (1986) 9.

[3] Annual Refining Report, Oil Gas J., March 18 (1991).

[4] G.L. Farina and E. Supp, Hydrocarbon Process., March (1992) 77.

[5] E.C. Kruissink, L.L. van Reijen and J.R.H. Ross, J. Chem. Soc., Faraday Trans. 1, 77 (1981) 649.

[6] L.E. Alzamora, J.R.H. Ross, E.C. Kruissink and L.L. van Reijen, J. Chem. Soc., Faraday Trans. 1, 77 (1981) 665.

[7] EC. Kruissink, L.E. Alzamora, S. Orr, E.B.M. Doesburg, L.L. van Reijen, J.R.H. Ross and G. van Veen, Stud. Surf. Sci. Catal., 3 (1979) 143.

[8] J.R.H. Ross, Catalysis, Spec. Period. Rep., Roy. Soc. Chem., London, (1985) 1.

[9] K.B. Mok, J.R.H. Ross and R.M. Sambrook, Stud. Surf. Sci. Catal., 16 (1983) 291.

[10] Dycat International, Technical information sheet on Midrex applications.

[11] G.E. Keller and M.M. Bhasin, J. Catal., 73 (1982) 9.

[12] W. Hinsen, W. Bytyn and M. Baerns, Proc. 8th Int. Congr. Catal., Berlin, 3 (1984) 581.

[13] T. Ito, J.-X. Wang, C.-H. Lin and J.H. Lunsford, J. Am. Chem. Soc., 109 (1985) 5062.
[14] J.A. Roos, A.J. Bakker, H. Bosch, J.G. van Ommen and J.R.H. Ross, Catal. Today, 1 (1987) 133.

[15] S.J. Korf, J.A. Roos, J.W.H.C. Derksen, J.A. Vreeman, J.G. van Ommen and J.R.H. Ross, Appl. Catal., 59 (1990) 291.

[16] S.J. Korf, J.A. Roos, L.J. Veltman, J.G. van Ommen and J.R.H. Ross, Appl. Catal., 56 (1989) 119.

[17] A.N.J. van Keulen, G.C. Hoogendam, K. Seshan, J.G. van Ommen and J.R.H. Ross, J. Chem. Soc., Chem. Commun., (1992) 1546; G.C. Hoogendam, Ph.D. Thesis, University of Twente, 1996.

[18] P. Pareira, S.H. Lee, G.A. Somorjai and H. Heinemann, Catal. Lett., 6 (1990) 255.

[19] K.M. Dooley and J.R.H. Koss, Appl. Catal. A, 90 (1992) 159.

[20] K.M. Dooley, S.-Y. Chen and J.R.H. Ross, J. Catal., 145 (1994) 402.

[21] M. Baerns and J.R.H. Ross, in J.M. Thomas and K.I. Zamaraev (Editors), Perspectives in Catalysis, Blackwell, Oxford, 1992, p. 315.

[22] F. Fischer and H. Tropsch, Brennstof. Chem., 3 (1928) 29.

[23] J.T. Richardson and S.A. Paripatyadar, Appl. Catal,, 61 (1990) 293.

[24] A.T. Ashcroft, A.K. Cheetham, M.L.H. Green and P.D.F. Vernon, Nature, 352 (1991).

[25] A.N.J. van Keulen, M.E.S. Hegarty, J.R.H. Ross and F.F. van den Oosterkamp, Natural Gas Conversion Meeting. South Africa, November 1995, in press.

[26] P.F. van den Oosterkamp, Q. Chen, J.A.S. Overwater, J.R.H. Ross and $\Lambda$.N.J. van Keulen, Symposium on Large Chemical Plants, Antwerp, September 1995, in press.

[27] V.A. Tsipouriari, A.M. Efstathiou, Z.L. Zhang and X.E. Verykios, Catal. Today, 21 (1994) 570.

[28] M. Masai, H. Kado, A, Miyaki, S. Nishiyama and S. Tsuruya, Stud. Surf. Sci. Catal., 36 (1988) 67.

[29] Platinum 1995, Johnson Matthey, London.

[30] V.H. Agreda, Acetic acid and its derivatives, Marcel Dekker, New York, 199.3, p. 225. 